\title{
Cultivating Students' Exploring Ability in Chemistry Teaching
}

\author{
Ru-ling ZHANG ${ }^{1, a, *}$ \\ ${ }^{1}$ Linyi University, Feixian, Shandong, China \\ alydxmfl@126.com
}

Keywords: Chemistry teaching, Exploring ability, Cultivate.

\begin{abstract}
One of the important tasks of current education is cultivating students' scientific exploring ability. Combined with the practical status of current chemistry teaching, this article put up with ideas that in chemistry teaching, we should cultivate students' ability of raising questions, of cooperative exploration, of conjectures and hypothesis, of experimental design, cultivating their manipulative ability, their reflection and appraisal ability, and finally promote students' exploring ability through the cultivation of the abilities above.
\end{abstract}

\section{Introduction}

The current educational task is beyond only imparting knowledge to students, but also is to make students grasp scientific learning method. Cultivating students' exploring ability has been one of the most important contents in the new teaching reform. But now, many junior students still follow the old learning model: class notes and doing exercises in the book after class. Rote learning makes them ignore the process of exploration. This does not mean that acquiring knowledge is not important, but by contrast, what matters much more is the promotion of ability. Because only with the promotion of the ability can students be propelled to acquire knowledge much more easily, and will be able to take use of the knowledge they have learned better [1].

\section{Cultivating Students' Ability of Raising Questions in Chemistry Teaching}

In terms of scientific exploration, raising questions is the prerequisite and the key matter. So to cultivate students' scientific exploring ability, the most important task is that students are able to raise questions.

\section{Cultivating Students' Question Awareness during the Process of Learning}

To raise questions, question awareness must be in the mind. While in the process of practical teaching, some teachers always raising questions by themselves instead of letting students ask, which makes students miss the opportunity of finding out questions, and kill their ability in finding out questions. To change such status, teachers should create atmosphere of raising questions, and enable students to generate interest in learning new knowledge. In such circumstance, students will learn to think self-consciously, and then in thinking can students find out questions continuously.

\section{Enhance Students' Ability of Raising Questions}

In the teaching process of chemistry, we must take full use of students' nature of curiosity and asking questions, and make students develop the habit of asking questions [2]. The concrete practices are as follows: 
Create good teaching environment, and make students glad to raise questions. Firstly, the teacher should change their role. In classroom teaching, teacher is the leader, not the dominator. Questions raised by students themselves are all the outcome of thinking, teacher should encourage such kind of behavior. Secondly, teachers should be passionate about every student that can raise questions. Thirdly, solve every student's questions carefully. Teachers can put up with their own opinions on questions worth research. Don't laugh at students who have raised wrong or inappropriate questions, their behavior of raising questions itself is valuable.

Make students grasp the method of raising questions. First of all, specific examples should be put up with to make students understand the structure of chemistry questions, make them know that there have limited scope in chemistry questions, when raising questions. The range of answer must be defined. Secondly, teachers should analyze the wrong questions raised by students, and gave some directions, to make students understand how to grasp the key point when expressing their questions. Thirdly, the chemistry discipline has chemical terms and chemical symbols, when expressing questions, students must make efforts to be correct and normal.

\section{Cultivating Students' Ability in Raising Questions Worth Exploring}

When students have already been good at raising questions, teachers should improve requirement, make students to raise questions worth exploring.

Lead students to analyze and appraise question worth exploring. Firstly, dissect and analyze the questions worth exploring, make students have a rudimentary knowledge of the question. Then tell students the standard of judging whether a question is worth exploring or not, and make students understand questions worth exploring rationally.

Lead students to appraise questions raised by themselves. Through appraising questions raised by themselves, students can feel what questions worth exploring looks like and on what basis it is raised.

\section{Cultivating Students' Ability of Conjectures and Hypothesis}

Scientific activities cannot exist without conjectures and hypothesis. To cultivate students' ability of conjectures and hypothesis, we can start from the two following aspects.

\section{Encourage Students to Conjecture and Hypothesize on the Basis of Knowledge and Experiences Students already have}

Teachers should encourage students to think questions in the way of divergent thinking, to conjecture and hypothesize scientifically, and make students understand the chemical knowledge in textbooks are generated through chemists' conjectures and hypothesis, through the test of practice, through continuous supplement and amendment. For example, the periodic table of the elements and the discovery of it [3].

\section{Teach Students the Way to Put Forward Conjectures and Hypothesis}

Induction. Simply speaking, Induction goes from the specific to the general. For instance, when learning electrolyte, through the experiment, we get the result that hydrochloric acid is strong electrolyte, and acetic acid is weak electrolyte. According to the experiment, students make such hypothesis: strong acid is strong electrolyte, while weak acid is weak electrolyte. Then, such hypothesis can be verified by experiment. 
Analogy. For instance, after studying the quality of metallic sodium, we can analogize the quality of lithium and potassium, and verified it by experiment.

\section{Cultivating Students' Ability of Experimental Design in Chemistry Teaching}

The experimental design requires students to take use of the knowledge they have learned, to think carefully and use their imagination to design experimental schemes that can verify the questions.

Provide students with opportunities of designing chemical experiments as much as possible [4]. In chemistry teaching, create more opportunities for students to design experiments, so as to make students design more experiments, thus we can help students to master the usual ways of experimental design, and improve their level of experimental design.

Train students to design chemical experiment in planning fashion. Firstly, students must be mentally prepared for the questions they are going to explore, how to explore, and when to explore; and, they should also get necessary chemicals and equipments ready. Secondly, when implementing exploring activities, it is better to divide the question to be explored into several small parts, then explore them respectively and solve them in fragments.

Encourage students to improve chemistry experimental design scheme continuously. Teacher should encourage every student to take active part in experimental design, and guide students to analyze schemes of their own and others, find out the advantages and disadvantages of each other, and make the experimental schemes better.

\section{Promoting Students' Manipulative Ability}

The promotion of students' basic experimental skill is the prerequisite of the promotion of students' manipulative ability. This demands teacher to arouse students' enthusiasm in chemistry teaching, and create much more opportunities for students to operate experiments, and should train students in basic experimental skill.

Besides, improve students' power of observation. First of all, teach students to make clear the aim of observation. Students tend to be excited when doing experiments, so when it comes to situations that there are many experiment phenomena, after the experiment, students may only remember the parts that they are interested in, while cannot understand the other phenomena. Secondly, teach students observation methods. Only with correct observation methods can students get the precise data. Only in this way can students keep in mind that what to observe and how to observe in experiment.

\section{Cultivating Students' Ability of Cooperative Exploration through the Way of Group Learning in Chemistry Teaching}

In the good atmosphere of asking questions, students will explore questions actively when questions appear. In the old teaching mode, teachers are responsible for raising questions, while students are responsible for answering their own conclusions. Such mode decreases the discussion and communication between students. The heroes in class can only be a minority of active students who do well at school. While majority of students becomes onlookers, actually they did not take part in the exploring activities.

However, group learning can avoid such flaws, the basic steps of implementing group learning are as follows: the first step, teacher creates appropriate atmosphere of asking questions, and make students to raise questions to be explored. The second step, 
teacher divide students into several groups, then begin the scientific exploration activities.

To implement scientific exploration activity, three tasks are to be finished. The first one is putting forward conjecture and hypothesis, the second one is designing verification scheme and conducting the verification, the third one is getting conclusions. Teacher should also participate in the process of group exploration, and give some hints to groups that have quite different views, and correct the relatively large deviations made by some group. After the exploration activity, the leader of every group should publish their conclusions, the problems they met during the process of exploration and their solution, then teacher organize students to reflect and evaluate on exploration activities of every group.

\section{Cultivating Students' Reflection and Appraisal Ability}

Reflection and appraise is an important part of scientific exploration. Only through reflection and appraise, can students notice the problems existed in the process of exploration, find out the solutions and the reason of failure.

Firstly, students should have the awareness of self-reflection on the process of exploration. For example, "The exploration activity has made success, and the reason is that the verification scheme is designed properly, and I will continue with my efforts"; "The exploration activity failed, it mainly because that my verification scheme is not designed well, other students do not have such problems. By contrast, find out the reason, and redesign a new verification scheme, then through experiment, the redesigned scheme is proved to be indeed much better."

\section{Summary}

Students should have the awareness of self-evaluation on the exploring results. Such awareness manifests as actively analyze whether the exploring results has solved the questions or not, whether the exploring result is right or not. We should take the scientific exploration as breakthrough of chemical curriculum reform, and advocate diversified learning approaches focusing on scientific exploration [5]. This will not only improve students' exploring ability continuously, but also will satisfy students' natural exploration, cultivate students' interest in chemistry, and unveil the mysterious yashmak of chemistry, this, is undoubtedly an important way to achieve the goal of chemical curriculum.

\section{Reference}

[1] Hao Yumei, Explorations and Practices of Cultivating Students' Ability of Raising Questions in Chemistry Teaching in Middle School [D], Northeast Normal University, 2004.

[2] Tian Xiuqing, Research on Cultivating Students' Exploring Ability in High School Chemistry Teaching [D]. Shandong Normal University, 2008

[3] Xie Jiemei, Research on Question Generation and Solution in Junior Middle School Science [D]. Yanbian University, 2010

[4] Qiu Yan, The Importance of Inquiry Teaching in Chemical Experiment Teaching in Middle School [J]. The Science Education Article Collects, 2009. (9): 194. 
[5] Du Chen, Promote Students' Scientific Literacy [J]. The New Curriculum, 2013, (3):113. 